\title{
Zinc therapy in dermatology: A Review and Update
}

\author{
Aryal $E^{1}$, Bhattarai $E^{1}$, Bhattarai $S^{1}$
}

1Department of Dermatology, Kathmandu Medical College Teaching Hospital, Sinamangal, Kathmandu, Nepal

\begin{abstract}
Zinc is a micronutrient used over the years for many dermatological conditions such as infections, inflammatory dermatoses, pigmentary disorders, neoplasias, etc. It is used in both elemental as well as salt form, either in topical or in oral form as a therapy. An average adult weighing $70 \mathrm{~kg}$ has a body zinc content of $1.4-2.3 \mathrm{gm}$. The role of zinc in deficiency disorders like acrodermatitis enteropathica is already established and used widely as treatment. Zinc has been identified as effective in the treatment of various disorders, but it cannot be used as the replacement for proven first-line treatment. Zinc can be used as an adjuvant therapy in many dermatological disorders. This is a narrative review where the various uses of zinc as therapy in dermatological disorders is highlighted.
\end{abstract}

Key words: Acrodermatitis Enteropathica; Micrconutrient; Zinc

\section{Introduction}

Z inc $(Z n)$ is an essential micronutrient for humans and its importance can be highlighted from the fact that it is an essential component of more than 300 metalloenzymes and over 2000 transcription factors that are needed for the regulation of lipid, protein and nucleic acid metabolism, and gene transcription. ${ }^{1}$ Its role in biology can be grouped into three general functional classes, namely catalytic, structural and regulatory functions. ${ }^{2}$ An average adult weighing $70 \mathrm{~kg}$ has a body zinc content of 1.4-2.3 gm. The recommended daily allowance of zinc for an average adult male is $11 \mathrm{mg}$ and the requirement increases from $8 \mathrm{mg} / \mathrm{d}$ to up to $12 \mathrm{mg} / \mathrm{d}$ in females during pregnancy and lactation. It is absorbed from the proximal jejunum and distal duodenum and helped by the presence of zinc binding ligands. It is excreted mainly through feces and in small amounts in urine and sweat. ${ }^{3}$

\section{Zinc as a therapy}

Various forms of zinc have been used as a mode of therapy either in topical or oral forms. Topical preparations like zinc oxide, calamine, or zinc pyrithione have been in use as photoprotecting, soothing agents

Funding: No

Conflict of Interest: No

\section{Address of Correspondence}

Dr. Elisa Bhattarai

Resident, Department of Dermatology, Kathmandu Medical College Teaching Hospital.

Phone No. 9846466254

E-mail: elisabhattarai91@gmail.com or as an active ingredient of antidandruff shampoos. The use of zinc is well established in acrodermatitis enteropathica, but over the years use of zinc has been expanded in various disorders. ${ }^{4}$ In this article we have highlighted the various dermatological uses of zinc therapy.

Acrodermatitis Enteropathica: It is a rare congenital form of zinc deficiency. The clinical manifestations of this disease usually start following weaning from breast feeding, when the protective effect of the $\mathrm{Zn}$ binding ligand from the mother's milk is no longer present. They include growth retardation, diarrhea, alopecia, and characteristic cutaneous lesions involving acral, periorificial, and anogenital areas, ${ }^{5}$ treatment with oral zinc (2-3 mg/kg/day) will cure all clinical manifestations within 1-2 weeks and needs to be continued up to adulthood for continuous supplementation and favorable long-term prognosis. ${ }^{4}$

Wart: Zinc can be used in both oral and topical form in treating warts without significant adverse effects.

Submitted: $17^{\text {th }}$ January 2021

Accepted: $10^{\text {th }}$ February 2021

Published: $20^{\text {th }}$ February 2021

How to cite this article

Aryal E, Bhattarai E, Bhattarai S. Zinc therapy in dermatology: A Review and Update. Nepal Journal of Dermatology, Venereology \& Leprology 2021;19(1):3-8. https://doi. org/10.3126/njdvl.v19i1.36118.

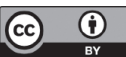

Licensed under CC BY 4.0 International License which permits use, distribution and reproduction in any medium, provided the original work is properly cited. 
Moniem et al. conducted a study in 50 people divided into two groups, one with oral zinc supplementation $10 \mathrm{mg} / \mathrm{kg}$ up to $600 \mathrm{mg}$ maximum daily dose for 1 month and the second group did not receive any treatment. The significant increase in serum zinc level in group I was associated with more clinical improvement in the warts. ${ }^{6}$ Mohamed et al. demonstrated that lesions treated with intralesional injection of $2 \%$ zinc sulfate solution. Among the 225 warts injected, 135 warts (60\%) cured from the first session, 51 warts (22.67\%) cured from the second session, and 12 warts (5.33\%) cured from the third session ${ }^{7}$

Cutaneous Lesihmaniasis: Bafghi et al. assessed the sensitivity of two parasite agents in cutaneous leishmaniasis: Leishmania major and L. tropica to zinc sulphate in vitro. Both parasite species showed sensitivity to zinc sulphate in vitro and in comparison, with the control group, their numbers were reduced. ${ }^{8}$ Sharquie et al. used oral zinc sulphate in doses of 2.5, 5 , and $10 \mathrm{mg} / \mathrm{kg} /$ day for 45 days among 104 patients with cutaneous leishmaniasis and observed cure rates of $83.9 \%, 93.1 \%$, and $96.9 \%$ for the $2.5 \mathrm{mg} / \mathrm{kg}, 5 \mathrm{mg} /$ $\mathrm{kg}$, and $10 \mathrm{mg} / \mathrm{kg}$ treatment groups, respectively, without significant adverse effects. ${ }^{9}$

Leprosy: Zinc is found to stimulate the production of IL-2 and induces a shift from Th2 to Th1 response. It has also been demonstrated to decrease the serum levels of TNF- $\alpha$ and inhibit the TNF- $\alpha$ induced apoptosis of peripheral blood mononuclear cells that helps in controlling the disease activity and reactional state.$^{10}$ In a study comprising patients with recurrent erythema nodosum leprosum additionally receiving zinc, steroids could be tapered off completely and the duration and severity of reaction were also reduced. ${ }^{11}$ Addition of oral zinc to antileprosy treatment too has been shown to improve therapeutic outcome. Oral zinc when given as an adjuvant to dapsone in lepromatous leprosy induced rapid lepromin conversion and bacterial clearance in the patients compared to the control group. The clinical improvement was also faster in patients receiving zinc as an adjuvant along with standard MDT. ${ }^{12}$

Herpes Simplex: In a study, 30 patients each group applied topical $\mathrm{ZnSO}_{4}$ in concentrations of $1 \%, 2 \%$, and $4 \%$, respectively, for 3 months. Ten patients of group $1\left(1 \% \mathrm{ZnSO}_{4}\right)$ showed recurrence, 6 patients in group 2 ( $2 \% \mathrm{ZnSO} 4)$, and only one patient in group 3 (4\% $\mathrm{ZnSO}_{4}$ ) showed recurrence. ${ }^{13}$ Ranjbar et al. stated that there was signifcant relationship between zinc level and recovery period in the recurrent herpes labialis patients. The lower the serum zinc level, the higher the duration of recovery. ${ }^{14}$
Dermatophytoses: Al Janabi et al. observed xerogel nanoparticles composed of $\mathrm{ZnO}$ had antidermatophytic action in specific concentrations. ${ }^{15}$ In the study, 30 patients with tinea corporis received topical $10 \%$ zinc sulfate solution twice daily for two months, complete cure response was observed in 13 (43.33\%) patients, partial response in 7 (23.34\%) patients and no response in 10 (33.33\%) patients while in placebo group the clinical response was two $(6.67 \%)$ patients with partial improvement and 28 (93.33\%) patients with no improvement. ${ }^{16}$

Bromhidrosis: Foot odor is a common sociomedical problem that affects the feet of human beings of different etiological factors. Owing to its antibacterial action, topical zinc sulphate has been tried and found effective in the management of axillary bromhidrosis and plantar malodor. Sharquie et al. in a single blinded placebo controlled therapeutic trial studied the efficacy of $15 \%$ zinc sulphate solution for foot malodor. Zinc sulfate solution $15 \%$ was applied to the sole and toe webs once daily for two weeks, three times per week for the next two weeks and followed by single application weekly as maintenance after clearance of odor for two months. Fifty-eight patients received zinc sulphate solution while the other 50 patients received a placebo solution. Thirty-five of the 50 (70\%) patients who completed the study showed complete clearance of foot odor compared to only $1(2 \%)$ subject in the placebo group and the difference was statistically significant. $^{17}$

Pityriasis Versicolor: Pityriasis versicolor (PV), also known as tinea versicolor, is a chronic and benign superficial fungal skin infection caused by Malassezia yeasts. Zinc pyrithione $1 \%$ is a proven treatment modality for pityriasis versicolor. Zinc pyrithione increases copper influx, which inactivates the fungi. ${ }^{18}$ Sharquie et al. observed in a study of 30 patients complete clinical and mycological cure after 3 weeks' treatment with once daily application of $15 \%$ topical zinc sulphate in patients with pityriasis versicolor while no patient in the placebo group showed any response. ${ }^{19}$

Acne Vulgaris: Zinc is an effective treatment of acne. ${ }^{20}$ Yee et al. observed that the patients who were treated with zinc had a significant improvement in mean inflammatory papule count compared to those who were not treated with zinc. There was no significant difference in the incidence of side effects of zinc supplementation vs comparators. Acne patients also have decreased serum zinc levels. ${ }^{21}$ Sayyafan et al. observed that erythromycin $2 \%$ with zinc acetate $1.2 \%$ as 'topical gel' and erythromycin $2 \%$ gel alone 
erythromycin treatment with zinc acetate was more effective than erythromycin alone with respect to reducing the number of acne lesions and severity grade of acne..$^{22}$ In a study, lactoferrin with vitamin $E$ and zinc was more effective than placebo. ${ }^{23}$

Rosasea: Rosacea is an inflammatory facial dermatosis with varied clinical features. ${ }^{24}$ In a randomized control trial, significant improvement was seen in 19 patients who received zinc sulfate $100 \mathrm{mg}$ orally thrice daily compared to placebo in total 25 patients ${ }^{25}$, while the other study did not show any significant advantage over placebo when zinc sulfate $220 \mathrm{mg}$ twice daily for 3 months in 44 patients. ${ }^{26}$

Uremic Pruritus: Uremic pruritus is a common and burdensome symptom for patients with kidney failure, affecting up to $46 \%$ of hemodialysis patients. ${ }^{27}$ Najafabadi et al. observed that zinc sulfate $440 \mathrm{mg} /$ day for 3 months is more effective than placebo for the relief of pruritus in patients under maintenance hemodialysis in a study of 40 people. ${ }^{28}$

Psoriasis: Zinc has been used for the management of psoriasis and psoriatic arthritis as well. Sadeghian et al. found a topical $0.25 \%$ zinc pyrithione cream, applied twice daily, effective for localized plaque psoriasis in a randomized double-blind controlled trial. The benefit was attributed to the antiproliferative effect of zinc pyrithione. $^{29}$

Eczema: Zinc plays a central role in skin integrity via barrier and immune mechanisms and may also be relevant in the pathogenesis of atopic dermatitis. ${ }^{30}$ Kim et al. randomized children with $A D$ and low hair zinc levels to receive oral zinc oxide supplementation or no zinc supplementation. The zinc supplementation group had a significant increase in hair zinc levels, as well as a significant improvement in the extent and severity of $A D .^{31}$

Seborrheic Dermatitis: Zinc has many properties that affect inflammatory processes, the immune system, and epithelial differentiation, and it has antifungal properties and antiandrogenic effects, all of which also contribute to the pathogenesis of SD. Gray et al. revealed lower zinc levels in SD patients compared with controls. ${ }^{32}$ The zinc salt of L-pyrrolidone carboxylate (zinc PCA) has long been used for its astringent and antifungal properties. It also has antioxidative and anti-inflammatory effects. Zinc PCA is a good option for patients with mild exudative seborrheic dermatitis. ${ }^{33}$

Molluscum Contagiosum: Safa and Darrieux showed that $\mathrm{Zn}$ oxide cream containing colloidal oatmeal extract was effective in the treatment of this viral infection. It has been demonstrated that oat extract has inhibitory effects on eicosanoid formation, expression of cytosolic phospholipase A2, and arachidonic acid mobilization in human keratinocytes. ${ }^{34}$

Melasma: Sharquie et al. revealed the efficacy of $10 \%$ $\mathrm{Zn}$ sulphate solution in the treatment of melasma. They reported that its effect was statistically significant $(P<.0005)$, and most of the patients maintained this improvement 3 months after cessation of therapy. It is likely that $\mathrm{Zn}$ is effective in the treatment of melasma due to its roles as anti-inflammatory, anti-oxidant, peeling, sun-screening, and healing agent. ${ }^{35}$

Vitiligo: Yaghoobi et al. suggested oral Zn sulphate as a new therapeutic option for vitiligo. They compared the efficacy of topical corticosteroids with and without oral $\mathrm{Zn}$ sulphate in the treatment of this disorder. Their study showed that the combination of topical corticosteroid and oral $\mathrm{Zn}$ was more effective than the topical steroid alone, but this difference was not statistically significant. Zinc in combination with other micronutrients plays an important role in the process of melanogenesis. ${ }^{36}$

Lichen Planus: The study concluded that oral zinc acetatae 50mg 2 times a day for 8 weeks therapy was associated with significant reduction in burning sensation and size of the lesion in symptomatic oral lichen planus. ${ }^{37}$ Mehdipour et al. compared $0.2 \%$ zinc mouthwash in combination with fluocinolone with a plain fluocinolone mouthwash in 20 patients with erosive lichen planus. It was observed that pain, irritation, and lesion surface area decreased in both groups. But the decrease in surface area with zinc mouthwash with fluocinolone was statistically more significant than that with fluocinolone alone. ${ }^{38}$

Premalignant and Malignant disorder: Sharquie et al. found a statistically significant response in the form of clearance of lesions with $25 \%$ topical zinc sulphate applied twice daily over the lesions for 12 weeks in 14 of 18 patients. ${ }^{39}$ Sharquie et al. observed improvement in skin lesions, including softening and lightening of the skin color, and clearance of solar keratosis and small malignancies were observed in 15 patients who continued the study during monthly follow up over a follow-up period of 2 years when $20 \%$ topical zinc sulphate was used in 19 patients with xeroderma pigmentosa. ${ }^{40}$

Ulcers and wound healing: Many studies have shown that zinc deficiency increases oxidative stress. Oxidative damage is a major cause of tissue 
injury and redox regulation plays a prominent role in wound repair. ${ }^{41}$ Meta-analysis of topical zinc therapy with zinc oxide paste-medicated dressings containing zinc concentration between $6-15 \%$ for chronic venous leg ulcers showed improved healing, although the authors point out that the studies were small and of sub-optimal quality. ${ }^{42}$

Bechets Disease: Sharquie et al. in a randomized, controlled, double-blind crossover trial comprising 30 subjects found oral zinc sulphate, $100 \mathrm{mg}$ given thrice daily for three months, to be an effective treatment modality for Behcet's disease without any major adverse effects. ${ }^{43}$

Alopecias: Lower serum zinc levels in patients with AA compared to controls have been identified. ${ }^{44}$ Sharquie et al. in a randomized placebo-controlled, doubleblinded crossover study used zinc sulphate in a dose of $5 \mathrm{mg} / \mathrm{kg} /$ day in three divided doses for a period of

\section{References}

1. Bibi Nitzan $Y$, Cohen AD. Zinc in skin pathology and care. J Dermatolog Treat. 2006;17(4):205-10. https://doi.org/10.1080/09546630600791434.

2. Cousins RJ. Zinc. In: Filer LJ, Ziegler EE, editors. Present Knowledge in Nutrition. 7th ed. Washington DC: International Life Science Institute Nutrition Foundation. 1996; 293-306.

3. Bangash HK and Sethi A. Zinc and skin health: an overview. In Handbook of Diet, Nutrition and the Skin 2012; 2 :178-195. https://doi. org/10.3920/978-90-8686-729-5_11

4. Gupta M, Mahajan VK, Mehta KS, Chauhan PS. Zinc therapy in dermatology: a review. Dermatol Res Pract. 2014;2014:709152. https://doi. org/10.1155/2014/709152

5. Kawamura T, Ogawa $Y$, Nakamura $Y$, Nakamizo $S$, Ohta $\mathrm{Y}$, Nakano $\mathrm{H}$, et al. Severe dermatitis with loss of epidermal Langerhans cells in human and mouse zinc deficiency. J Clin Invest 2012. 122:722732 https://doi.org/10.1172/JCI58618

6. Moniem EA, Genedy RM, Moussa R. Oral zinc sulfate in the treatment of recalcitrant warts. Egypt J Dermatol Venerol 2016;36:34-8 https:// doi.org/10.4103/1110-6530.202637

7. Mohamed, EM, Tawfik KM, \& Mahmoud AM. The Clinical Effectiveness of Intralesional Injection of $2 \%$ Zinc Sulfate Solution in the Treatment of Common Warts. Scientifica 2016, 1-4. https://doi. org/10.1155/2016/1082979 six months and observed a visible clinical response in $62 \%$ of patients with alopecia areata. ${ }^{45}$ In a study 30 mg zinc gluconate + sulfur amino acids + vitamin D / day for at least 1 year results progressive hair growth at 3-5 months. ${ }^{46}$ Hair count results show a modest and sustained improvement in hair growth with daily use of $1 \%$ pyrithione zinc shampoo over a 26 -week treatment period. ${ }^{47}$

\section{Conclusion}

Over many years, zinc has been used as therapeutic modalities in various dermatological disorders. Efficacy of zinc therapy is the most studied topic for the treatment of acne but there are many variables and results. Although zinc has been identified as effective in the treatment of various disorder, but it cannot be used as the replacement for proven $1^{\text {st }}$ line treatment. Thus, Zinc can be used as an adjuvant therapy in many dermatological disorders either in topical and systemic form.

8. Fattahi Bafghi A, Noorbala M, Taghi Noorbala M, \& Aghabagheri M. Anti leishmanial Effect of Zinc Sulphate on the Viability of Leishmania tropica and L. major Promastigotes. Jundishapur Journal of Microbiology 2014: 7(9): e11192. https://doi. org/10.5812/jjm.11192

9. Sharquie KE, Najim RA, Farjou IB, and Al-Timimi D. Oral zinc sulphate in the treatment of acute cutaneous leishmaniasis. Clin Exp Dermatol 2001:26(1);21-26. https://doi.org/10.1046/ j.1365-2230.2001.00752.x

10. Gupta A, Sharma VK, Vohra H, and Ganguly NK. Inhibition of apoptosis by ionomycin and zinc in peripheral blood mononuclear cells (PBMC) of leprosy patients. FEMS Immunology and Medical Microbiology.1999: 24; 49-55. https://doi. org/10.1111/j.1574-695X.1999.tb01264.x

11. Mathur NK, Bumb RA, and Mangal HN. Oral zinc in recurrent erythema nodosum leprosum reaction. Leprosy In India 1983:55( 3); 547-552.

12. Mathur NK, Bumb RA, Mangal HN, and Sharma ML. Oral zinc as an adjunct to dapsone in lepromatous leprosy. Int J of Lepr 1984: 52( 3);331-338

13. Mahajan BB, Dhawan M, Singh R. Herpes genitalis - Topical zinc sulfate: An alternative therapeutic and modality. Indian J Sex Transm Dis AIDS 2013 Jan;34(1):32-4. https://doi.org/10.4103/02537184.112867

14. Ranjbar Z, Zahed M, Ranjbar MA, \& Shirmardan Z. Comparative study of serum zinc concentration in recurrent herpes labialis patients and healthy 
individuals. BMC Oral Health 2020: 20(1). https:// doi.org/10.1186/s12903-020-01277-2

15. Al-Janabi AAHS, Bashi AM. Development of a new synthetic xerogel nanoparticles of silver and zinc oxide against causative agents of dermatophytoses. J Dermatolog Treat 2019 May;30(3):283-287 https://doi.org/10.1080/095 46634.2018.1506079

16. Khalifa E. Sharquie, Adil A. Noaimi, Sarmad A. AlHashimy, Iqbal G. F. Al-Tereihi Treatment of Tinea Corporis by Topical $10 \%$ Zinc Sulfate Solution. Iraqi Postgraduate Medical Journal 2013: 12 (2): 247-250

17. Sharquie KE, Noaimi AA, Hameed, SD. Topical $15 \%$ zinc sulfate solution is an effective therapy for feet odor. Journal of Cosmetics, Dermatological Sciences and Applications. 2013:3;203-208. https://doi.org/10.4236/jcdsa.2013.33031

18. Bamford JTM, Flores-Genuino RNS, Ray S, et al. Interventions for the treatment of pityriasis versicolor. Cochrane Database Syst Rev 2018:(6);CD011208. https://doi. org/10.1002/14651858.CD011208.pub2

19. Sharquie KE, Al-Dori WS, Sharquie IK, and AINuaimy AA. Treatment of pityriasis versicolor with topical $15 \%$ zinc sulfate solution. Iraqi Journal of Community Medicine 2008: 21; 61-63.

20. Cervantes J, Eber AE, Perper M, Nascimento VM, Nouri K, Keri JE. The role of zinc in the treatment of acne: A review of the literature. Dermatol Ther 2018 Jan;31(1). https://doi.org/10.1111/ dth.12576

21. Yee BE, Richards P, Sui JY, Marsch AF. Serum zinc levels and efficacy of zinc treatment in acne vulgaris: a systematic review and metaanalysis. Dermatol Ther 2020:33(6) https://doi. org/10.1111/dth.14252

22. Sayyafan MS, Ramzi M, Salmanpour R. Clinical assessment of topical erythromycin gel with and without zinc acetate for treating mild-tomoderate acne vulgaris. J Dermatolog Treat 2020 Nov;31(7):730-733. https://doi.org/10.1080/095 46634.2019.1606394

23. Chan H, Chan G, Santos J, Dee K, Co JK. A randomized, doubleblind, placebo-controlled trial to determine the efficacy and safety of lactoferrin with vitamin $E$ and zinc as an oral therapy for mild to moderate acne vulgaris. Int J Dermatol 2017;56(6):686-90. https://doi.org/10.1111/ ijd.13607

24. Sarkar R, Podder I, Jagadeesan S. Rosacea in skin of color: A comprehensive review. Indian J Dermatol
Venereol Leprol 2020;86:611-621 https://doi. org/10.4103/ijdvl.IJDVL_769_19

25. Sharique KE, Najim RA, Al-Salman HN. Oral zinc sulphate in the treatment of rosacea: A double blind placebo controlled study. Int J Dermatol 2006;45:857-61. https://doi.org/10.1111/j.13654632.2006.02944.x

26. Bamford JT, Gessert CE, Haller IV, Kruger K, Johnson BP. Randomized, double-blind trial of $220 \mathrm{mg}$ zinc sulfate twice daily in the treatment of rosacea. Int J Dermatol 2012;51:459-62. https:// doi.org/10.1111/j.1365-4632.2011.05353.x

27. Simonsen $E$, Komenda $P$, Lerner B, Askin N, Bohm C, Shaw J, et al. Treatment of Uremic Pruritus: A Systematic Review. Am J Kidney Dis 2017;70(5): 638-655. https://doi.org/10.1053/j. ajkd.2017.05.018

28. Najafabadi MM, Faghihi G, Emami A, Monghad M, Moeenzadeh F, Sharif N, et al. Zinc Sulfate for Relief of Pruritus in Patients on Maintenance Hemodialysis. Ther Apher and Dial 2012; 16(2):142-145. https://doi.org/10.1111/j.17449987.2011.01032.x

29. Sadeghian G, Ziaei $H$, and Nilforoushzadeh MA. Treatment of localized psoriasis with a topical formulation of zinc pyrithione. Acta Dermatovenerol Alp Pannonica 2011;20(4) :187190.

30. Gray NA, Dhana A, Stein DJ, Khumalo NP. Zinc and atopic dermatitis: a systematic review and meta analysis. JEADV 2019;33: 1042- 1050 https://doi. org/10.1111/jdv.15524

31. Kim JE, Yoo SR, Jeong MG, Ko JY, Ro YS. Hair zinc levels and the efficacy of oral zinc supplementation in patients with atopic dermatitis. Acta Derm Venereol 2014; 94: 558-562. https://doi. org/10.2340/00015555-1772

32. Aktaş KE, Aksu CA. Serum zinc levels in seborrheic dermatitis: a case-control study. Turk J Med Sci 2019 Oct 24;49(5):1503-1508. https://doi. org/10.3906/sag-1906-72

33. Takino Y, Okura F, Kitazawa M, Iwasaki K, Tagami H. Zinc L-pyrrolidone carboxylate inhibits the UVAinduced production of matrix metalloproteinase-1 by in vitro cultured skin fibroblasts, whereas it enhances their collagen synthesis. Int J Cosmet Sci 2012;34(1):23-8. https://doi.org/10.1111/j.14682494.2011.00676.x

34. Safa G, Darrieux L. Successful treatment of molluscum contagiosum with a zinc oxide cream containing colloidal oatmeal extracts. 
Indian J Dermatol 2010;55: 295-296 https://doi. org/10.4103/0019-5154.70679

35. Sharquie KE, Al-Mashhadani SA, Salman HA. Topical $10 \%$ zinc sulfate solution for treatment of melasma. Dermatol Surg 2008;34: 1346-1349 https://doi.org/10.1111/j.15244725.2008.34287.x

36. Yaghoobi R, Omidian M, Bagherani N. Comparison of therapeutic efficacy of topical corticosteroid and oral zinc sulfate-topical corticosteroid combination in the treatment of vitiligo patients: a clinical trial. BMC Dermatology 2011; 11: 7. https://doi.org/10.1186/1471-5945-11-7

37. Kanikella PS, Kammari A, Waghamare RS. Zinc therapy in treatment of symptomatic oral lichen planus. Inddian Dermatol Online J 2019; 10:174-7

38. Mehdipour M, Taghavi AZ, Bahramian JA, Yazdani F, Pouralibaba KS. Comparison of the effect of mouthwashes with and without fluocinolone on the healing process of erosive oral planus. Journal of Dental Research, Dental Clinics, Dental Prospects 2010; 4:25-28.

39. Sharquie KE, Al-Mashhadani SA, Noaimi AA, Hasan AA. Topical zinc sulphate (25\%) solution: a new therapy for actinic keratosis. J Cutan Aesthet Surg 2012 Jan;5(1):53-6.. https://doi. org/10.4103/0974-2077.94331

40. Sharquie KE, Noaimi AA, Kadir NO. Topical therapy of xeroderma pigmentosa with $20 \%$ zinc sulfate solution. Iraqi Journal of Postgraduate Medicine 2008; 7:231-237.

41. Lin $\mathrm{PH}$, Sermersheim $M$, Li $H$, Lee $P$, Steinberg $\mathrm{S}$, Ma J. Zinc in Wound Healing Modulation.
Nutrients 2017;10(1) https://doi.org/10.3390/ nu10010016

42. O'Connor S, MurphyS. Chronic venous leg ulcers: Is topical zinc the answer? A review of the literature. Adv. Skin Wound Care 2014;27:35-44. https://doi. org/10.1097/01.ASW.0000439173.79541.96

43. Sharquie KE, Najim RA, Al-Dori WS, Al-Hayani RK. Oral zinc sulfate in the treatment of Behçet's disease: a double blind cross-over study. J Dermatol 2006;33(8):541-546. https://doi. org/10.1111/j.1346-8138.2006.00128.x

44. Abdel Fattah NSA, Atef MM, Al-Qaradaghi SMQ. Evaluation of serum zinc level in patients with newly diagnosed and resistant alopecia areata. Int J Dermatol 2016;55:24-29 https://doi. org/10.1111/ijd.12769

45. Sharquie KE, Noaimi AA, Shwail ER. Oral Zinc Sulphate in Treatment of Alopecia Areata (Double Blind; Cross-Over Study). J Clin Exp Dermatol Res 2012;3:150 https://doi.org/10.4172/21559554.1000150

46. Lux-Battistelli C. Combination therapy with zinc gluconate and PUVA for alopecia areata totalis: an adjunctive but crucial role of zinc supplementation. Dermatol Ther 2015;28:235238. https://doi.org/10.1111/dth.12215

47. Berger RS, Fu JL, Smiles KA, Turner CB, Schnell BM, Werchowski KM, Lammers KM. The effects of minoxidil, $1 \%$ pyrithione zinc and a combination of both on hair density: a randomized controlled trial. Br J Dermatol. 2003 Aug;149(2):354-62. https:// doi.org/10.1046/j.1365-2133.2003.05435.x 